\title{
Significance of Immunohistochemical Biomarker in Breast Carcinoma from a Single Tertiary Care Hospital of Southern Assam
}

\section{Naiding Momota}

Silchar Medical College and Hospital

Choudhury Biswadeep

Silchar Medical College and Hospital

\section{Bezbaruah Babul}

Silchar Medical College and Hospital

Nivedita Dasgupta ( $\square$ nivedita.dasgupta24@gmail.com )

Silchar Medical College and Hospital https://orcid.org/0000-0002-2699-3392

\section{Deuri Biman}

Silchar Medical College and Hospital

\section{Sharma Jyotika}

Silchar Medical College and Hospital

\section{Research}

Keywords: Estrogen receptor, progesterone receptor, HER2/neu, infiltrating ductal carcinoma, breast.

Posted Date: June 25th, 2021

DOI: https://doi.org/10.21203/rs.3.rs-630094/v1

License: (1) This work is licensed under a Creative Commons Attribution 4.0 International License.

Read Full License 


\section{Abstract}

Background:

Breast carcinoma is the most common malignancy in female worldwide, leading cause of death in women.immunohistochemistry plays a very important role in the prognostication and treatment determination of breast carcinoma patients.

Objective:

To analyze the immunohistochemical markers in invasive carcinoma of breast and to correlate the expression of hormonal receptors with age of the patient, tumor size, histological grade and lymph node metastasis.

Materials and method:

The study was conducted on 88 infiltrating ductal breast carcinoma sample in a tertiary care hospital of Southern Assam for a period of two year (January2018- December 2019). Data including age, tumor size, and histologic grade and lymph node status retrieved from pathology department. Chi- square was used to determine the statistical significance between ER/PR status HER2/neu status along with their correlation with various clinicopathological parametres with respect to infiltrating ductal breast carcinoma.

Result:

The mean age of the patients was 56.6 years. We observed correlation between ER and PR expression with age, tumor size, tumor grade. There was correlation between HER2/neu expression and age only. None of the markers showed correlation with lymph node involvement $(P>0.05)$.

Conclusion:

Our findings showed the importance of biomarkers (ER, PR, HER2/neu) expression as prognostic factors for therapeutic decision.

\section{Introduction}

Breast cancer is a major concern and one of the leading causes of cancer related death throughout the world. Breast cancer like many other types of cancer is a complex heterogeneous disease controlled by a multitude of genetic and epigenetic alterations [1]. During the past two decades the mortality rate has declined significantly, primarily due to the early use of adjuvant chemotherapy as well as detection of earlier stage tumours due to increased screening.[2] Prognosis and management of breast cancer is influenced by the classical variables such as histological type and grade, tumour size, lymph node status, and status of hormonal receptors, Estrogen receptors (ER) and progesterone receptors (PR) of the tumour and more recently Her2/neu oncoprotein status.[3] ER expression is undoubtedly the most important biomarker in breast cancer, because it provides the index for sensitivity to endocrine treatment. ER positive 
tumours ( $80 \%$ of breast cancer) use the steroid hormone estradiol as their main growth stimulus; ER is therefore direct target of endocrine therapies. PR expression is strongly dependent on the presence of ER. Tumours expressing PR but not ER are uncommon and represent $<1 \%$ of all breast cancer.

The tumors that are estrogen receptor (ER) positive and/or progesterone receptor (PR) positive have lower risks of mortality after their diagnosis compared to women with ER and/or PR negative disease. Clinical trials have also shown that the survival advantage for women with hormone receptor-positive tumors is enhanced by treatment with adjuvant hormonal and/or chemotherapeutic regimens [4]. In breast cancer the average incidence of estrogen receptor and progesterone receptor positivity is $57 \%$ and $43 \%$ respectively as shown in the studies. However, lower rates of positive estrogen and progesterone receptor breast cancers are found in Indian population from the western literature. The frequency of negative estrogen receptor and progesterone receptor is much more common in India (46.5\%) than in the West $(10 \%)$. Breast cancer patients of Indian origin tend to be younger, tumors are often large when first diagnosed, and of a high grade as compared to western series [5].

The purpose of this study was to analyze the immunohistochemical markers in invasive carcinoma of breast and to correlate the expression of hormonal receptors with age of the patient, tumor size, histological grade and lymph node metastasis.

\section{Material And Methods Study Design}

Eighty eight patients with a diagnoisis of infiltrating ductal carcinoma of breast in a tertiary care hospital of Southern Assam over a period of two year (January2018- December2019) were included in this study. Data including age, tumor size, and histologic grade and lymph node status retrieved from pathology department. We analysed the expression of ER, PR, and HER2/neu by immunhistoochemistry (IHC), with each other and to various clinicopathological parametres. Institutional ethical committee approval was taken

\section{Inclusion criteria}

All patients with histologically confirmed infiltrating ductal carcinoma of the breast were included in the study.

\section{Exclusion criteria}

Patients with inflammatory breast lesions, posttraumatic breast lesions, benign breast diseases and patients with breast cancer who received neoadjuvant chemotherapy were excluded from the study.

Paraffin blocks containing cancer tissue were selected from histopathologically confirmed cases of infiltrating ductal carcinoma. After preparing slides from blocks, immunohistochemical staining was done for ER, PR, and HER2/neu by standard procedure [6].

\section{Preparation of slides}


Paraffin sections were cut and mounted on salinized slides. Slides were melted at $65^{\circ} \mathrm{C}$ and then dipped into xylene to remove the paraffin. After rehydrating tissues, slides were washed with distilled water. Then, slides were dipped into a fresh aqueous solution of $3 \%$ peroxide for 3 min and rinsed with Tris buffer.

\section{Antigen retrieval and detection of antigens}

Heat retrieval was done with citrate buffer in the Decloaking chamber for 40 min at $95^{\circ} \mathrm{C}$ and then brought to room temperature after removing from the Decloaking chamber and by placing the slides in Tris-Saline buffer. $1 \%$ mouse serum was added to the tissue section to block nonspecific immunostaining. The sections were exposed to the primary antibody for about $1 \mathrm{~h}$, and then primary antibody was washed with Tris buffer.

\section{Secondary detection of the primary antibody}

Sections were incubated with biotinylated mouse anti-species antibody for $10 \mathrm{~min}$, and then rinsed in Tris buffer. A solution of chromogen, 3, 3'-diaminobenzidine (DAB) at $1 \mathrm{mg} / \mathrm{ml}$ in Tris buffer with $0.016 \%$ fresh $\mathrm{H}_{2} \mathrm{O}_{2}$ was prepared and added to the slides. DAB from the slides was washed with tap water.

\section{Counterstaining}

A solution of hematoxylin diluted 1:1 with distilled water was made slides were dipped into hematoxylin solution for staining. Then, slides were washed in distilled water and dehydrated by dipping in ethanol. Washed in xylene and coverslip was applied for viewing and reporting

Reporting

Reporting done as per ER/PR scoring system and criteria as per Allred scoring system [7].

\section{Proportion score}

0 - No cells are ER + ve.

$1-\leq 1 \%$ of cells are ER + ve.

$2-1-10 \%$ of cells are ER + ve.

$3-11-33 \%$ of cells are ER + ve.

$4-34-66 \%$ of cells are ER + ve.

$5-67-100 \%$ of cells are ER + ve.

\section{Intensity score}

0 - Negative. 
$1-$ Weak.

2 - Intermediate.

3 - Strong.

Interpretation

Total (proportion score + intensity score).

$0-2=$ Negative; $3-8=$ Positive

Human epidermal growth factor receptor-2/neu scoring system and criteria according to the American Society of Clinical Oncology College of American Pathologists guidelines [8]

$0=$ no staining or incomplete faint and barely perceptible in $<10 \%$ of tumor cells.

$1+=$ incomplete membrane staining which is faint and barely perceptible and within $>10 \%$ of tumor cells.

$2+=$ circumferential membrane staining that is incomplete and/or weak/moderate and within $>10 \%$ of the invasive tumor cells; or complete and circumferential membrane staining that is intense and within $\leq 10 \%$ of the invasive tumor cells.

$3+=$ circumferential, complete, and intense staining and within $>10 \%$ of tumor cells.

FISH will be done for equivocal HER2/neu positivity. Hence, HER2/neu $2+$ was taken as negative along with HER2/neu 0 and $1+$. Only $3+$ on IHC was taken as positive.

Statistical analysis

Chi- square was used to determine the statistical significance between ER/PR status HER2/neu status along with their correlation with various clinicopathological parametres such as patient's age, tumor size, tumor grade and axillary lymph node status with respect to infiltrating ductal carcinoma breast. A value of $P<0.05$ was considered as statistically significant.

\section{Results}

\section{Receptor status}

Fifty tumors were ER- positive and thirty eight were ER- negative. ER- positive tumors showed weak, moderate to strong nuclear positivity in $>1 \%$ of tumor cells (Fig. 1 ).

Forty six tumors were PR positive and forty two were PR negative. PR poisitive cases showed weak, moderate to strong nuclear positivity in $>1 \%$ of tumor cells (Fig. 2). Seven tumors that were positive for HER2/neu showed complete and intense staining and within $>10 \%$ of tumors cells (Fig. 3 ). 
Out of 88 cases, 46 cases were ER and PR positive, 38 cases were negative for both ER and PR. 4 cases showed different expressions of ER and PR.

Age

Patients were in the age group between 24 and 80 years, with mean age 56.6yrs years. The majority $35.22 \%, 29.54 \%$ were in the age group $51-60$ and $>60$ years respectively. About $82 \%$ ER positive and $80.43 \%$ PR positive cases were of age group > 50 years whereas $57.14 \%$ HER2/neu positive were in age < 40 years. (Table 1). It was statistically concluded that ER, PR, and HER2/ neu expression shows significant correlation with age.

Table 1

Age Vs ER, PR and HER2/neu expression

\begin{tabular}{|llllllllll|}
\hline $\begin{array}{l}\text { Age } \\
\text { (years })\end{array}$ & ER & \multicolumn{9}{c}{ PR } & \multicolumn{5}{c|}{ HER2/neu } \\
\cline { 2 - 10 } & positive & negative & total & positive & negative & total & positive & negative & Total \\
\hline$<40$ & 3 & 12 & 15 & 3 & 12 & 15 & 4 & 11 & 15 \\
\hline $41-50$ & 6 & 10 & 16 & 6 & 10 & 16 & 2 & 14 & 16 \\
\hline $51-60$ & 21 & 10 & 31 & 18 & 13 & 31 & 1 & 30 & 31 \\
\hline$>60$ & 20 & 6 & 26 & 19 & 7 & 26 & 0 & 26 & 26 \\
\hline Total & 50 & 38 & 88 & 46 & 42 & 88 & 7 & 81 & 88 \\
\hline$\chi^{2}$, df, $P$ & $16.51,3,0.0008$ & & $21.95,3,0.00006$ & & $10.84,3,0.0126$ & \\
\hline
\end{tabular}

\section{Tumor size}

The average tumor size was $4.1 \mathrm{~cm}$. About $48 \%$ ER positive and $56 \%$ PR positive tumors were of size between 2 and $5 \mathrm{~cm}$ whereas approx. $71 \%$ of HER2/neu tumors were of size $<2 \mathrm{~cm}$. Correlation of expression of ER, PR, HER2/neu compared to tumor size is shown in Table 2. So there exist statistically significance between tumor size and correlation of expression of ER, PR and HER/2neu. 
Table 2

Tumor size Vs ER, PR and HER2/neu expression

\begin{tabular}{|llllllllll|}
\hline $\begin{array}{l}\text { Tumor } \\
\text { size } \\
(\mathrm{mm})\end{array}$ & ER & \multicolumn{4}{c}{ PR } & \multicolumn{5}{c|}{ HER2/neu } \\
\cline { 2 - 10 } & positive & negative & total & positive & negative & total & positive & negative & total \\
\hline$<2$ & 20 & 8 & 28 & 15 & 13 & 28 & 5 & 23 & 28 \\
\hline $2-5$ & 24 & 16 & 40 & 26 & 14 & 40 & 2 & 38 & 40 \\
\hline$>5$ & 6 & 14 & 20 & 5 & 15 & 20 & 0 & 20 & 20 \\
\hline Total & 50 & 38 & 88 & 46 & 42 & 88 & 7 & 81 & 88 \\
$\chi^{2}, \mathrm{df}, \mathrm{P}$ & $8.36,2,0.0153$ & & $12.41,2,0.0021$ & & $5.95,2,0.5104$ & \\
\hline
\end{tabular}

ER-Esterogen receptor, PR- Progesterone receptor, HER2/neu- Human epidermal growth factor receptor

\section{Tumour grade}

. In this study, according to Nottingham Modified Bloom-Richardson System score, $42 \%$ of the tumors were in Grade II followed by Grade III (32\%) and then Grade I (26\%). Correlation of expression of ER, PR, HER2/neu compared to tumor grade is shown in Table 3. There is statistically significance between tumor grade and ER, PR expression, whereas there exists no significance between tumor grade and HER/2 neu expression.

Table 3

Tumor grade Vs ER, PR and HER2/neu expression

\begin{tabular}{|llllllllll|}
\hline Grade & ER & \multicolumn{4}{c}{ PR } & \multicolumn{5}{c|}{ HER2/neu } \\
\cline { 2 - 10 } & positive & negative & total & positive & negative & total & positive & negative & total \\
\hline I & 15 & 8 & 23 & 13 & 10 & 23 & 1 & 22 & 23 \\
\hline II & 27 & 10 & 37 & 24 & 13 & 37 & 2 & 35 & 37 \\
\hline III & 8 & 20 & 28 & 9 & 19 & 28 & 4 & 24 & 28 \\
\hline Total & 50 & 38 & 88 & 46 & 42 & 88 & 7 & 81 & 88 \\
$\chi^{2}$,df, P & $13.71,2,0.0010$ & & $7.064,2,0.0292$ & & $2.25,2,0.1336$ & \\
\hline
\end{tabular}

\section{Axillary lymph node status}

All the infiltrating ductal carcinoma cases were evaluated for association of axillary lymph nodes metastasis and observed that out of 50 ER positive cases, 18 were axillary lymph nodes positive and 19 out of 46 positive PR cases had positive axillary lymph nodes. Out of 7 HER2/neu positive cases, 2 has axillary lymph node metastasis. Correlation of expression of ER, PR, HER2/neu compared to axillary lymph 
node status is shown in Table 4. It was concluded that correlation of expression of ER, PR and HER2/neu compared to axillary lymph node status was not significant.

Table 4

Lymph node status Vs ER, PR and HER2/neu expression

\begin{tabular}{|c|c|c|c|c|c|c|c|c|c|}
\hline \multirow{2}{*}{$\begin{array}{l}\text { Lymph } \\
\text { node } \\
\text { status }\end{array}$} & \multicolumn{3}{|l|}{ ER } & \multicolumn{3}{|l|}{ PR } & \multicolumn{3}{|c|}{ HER2/neu } \\
\hline & positive & Negative & total & positive & negative & total & positive & Negative & total \\
\hline Positive & 18 & 15 & 33 & 19 & 14 & 33 & 2 & 31 & 33 \\
\hline Negative & 32 & 23 & 55 & 27 & 28 & 55 & 5 & 50 & 55 \\
\hline Total & 50 & 38 & 88 & 46 & 42 & 88 & 7 & 81 & 88 \\
\hline$\chi^{2}, \mathrm{df}, \mathrm{P}$ & \multicolumn{3}{|c|}{$0.105,1,0.74591$} & \multicolumn{3}{|c|}{$0.595,1,0.44049$} & \multicolumn{3}{|c|}{$0.26,1,0.61012$} \\
\hline
\end{tabular}

ER- Esterogen receptor, PR- Progesterone receptor, HER2/neu- Human epidermal growth factor receptor

\section{Discussion}

Female breast cancer is the most common malignancy worldwide, with over two million cases diagnosed in 2018 [9].

Breast cancer is the most common cancer in female, representing approximately $25 \%$ of all cancers. It is also ranked number one cancer among Indian females with age adjusted incidence rate of 25.8 per 1 , 00,000 women and mortality 12.7 per 1,00,000 women [10]. Treatment of breast cancer includes combined therapy; surgery, radiotherapy, chemotherapy, endocrine therapy, and targeted therapy and so forth. Hormone therapy can be started before surgery (as neoadjuvant therapy) or used after surgery (as adjuvant therapy) or as a prophylactic treatment of high risk populations as in BRCA mutation carriers. Evaluation of hormone receptor on surgically resected specimen or core biopsy material is essential to assess the utility of hormone therapy and thus the College of American Pathologists and American Society of Clinical Oncology recommend ER and PR testing for all newly diagnosed cases of invasive breast cancer and breast cancer recurrences [11].

Various biomarkers such as hormone receptors, vascular endothelial growth factors, epithermal growth factor, tumor suppressor genes, multidrug resistant genes and adhesion molecules have been identified [12]. Currently, determination of estr ogen receptor (ER), progesterone receptor (PR) and human epidermal receptor growth factor 2 (HER2/neu) receptor is routine in the diagnosis of breast cancer [13] with atleast $1 \%$ positivity is necessary for commencement for hormone therapy.

ER is a biomarker found in over $56.82 \%$ of infiltrating breast cancer in this study and contributes significantly to its pathobiology. ER positivity makes it responsive to hormonal therapy, resulting in a more favourable outcome. PR, like ER, is also a transcription factor, which is largely controlled by ER and to a lesser extent by growth factors. About $43.8 \%$ of infiltrating breast cancers show PR positivity. PR 
commonly coexists with ER. Studies from other region have documented lower positivity for ER and PR receptors. Desai et al [14] from India have reported $32.6 \%$ and $46.1 \%$ positivity for ER and PR respectively. Another study by Suvarchala et al [15] from South India showed $46.87 \%$ ER positivity and $43.75 \%$ PR positivity Similarly, a study from Sri Lanka by Mudduwa [16] have reported $45.7 \%$ ER positive and $48.3 \%$ PR positive tumors. Another study from western India have also reported $44.6 \%$ ER positive and $40.4 \%$ PR positive tumors [17]. In contrast, study from Bahrain reported high positivity for ER (72.6\%), PR (71\%) and HER2/neu (51\%) [18].

HER2/neu has the potential of enhancing proliferation and survival of tumor cells. In this study its overexpression occurs in about $7.95 \%$ of infiltrating breast cancer, results in a more aggressive growth and poor response to treatment. In this study the sample showing equivocal HER2/neu expression will be evaluated by fluorescence in situ hybridization. Unlike our study, Ranvijay et al [19] and Rashmi et al [20] reported $34.2 \%$ and $69.2 \%$ HER2/neu expression.

The mean age of breast cancer is 56.6yrs in our study which is much lower than the mean age of 62 year reported in UK [21] whereas in the US [22], peak is observed at the age 75 years. Our study corroborates with the study done by Elsayed et al [23] at Egypt where the mean age is 50.4 years. In India the incidence rates begin to rise in the early thirties and peak at ages 50-64 years. Though the reason entirely is still not clear but a major factor could be ignorance, lack of awareness and under reporting amongst the elderly population in India. Majority of ER and PR positive cases were of age $>60$ years and HER2/neu positive were of age $<40$ years, as seen in the study conducted by Alzaman et al [18]. A significant correlation was observed between age of the patient and ER (0.000), PR (0.000) and Her2/neu (0.012) expression as shown in studies by Dodiya et al [24].

Tumor size was $1-8.9 \mathrm{~cm}$, with average size $4.1 \mathrm{~cm}$. In this study significant correlation expression was seen between tumor size and ER $(P=0.015)$ and $P R(P=0.002)$. In contrary to the study by Ariga et al [25], we found correlation between tumor size and ER, PR expressions. However our result was similar with Bhatavdekar et al [26] findings.

Thirty seven tumors were of Grade II followed by 28 and 23 tumors were of Grade III and Grade I respectively. In contrary to other studies from developed country where well differentiated breast cancers are more common than poorly differentiated because of the availability of routine screening and awareness which has led to the detection at the early stage [27]. The majority of ER positive cases (54\%) were observed in Grade II carcinomas. Most PR positive cases (52.17\%) were also seen in Grade II, whereas most HER2/neu positive cases (57.14\%) were seen in Grade III. There was seen significant correlation between tumor grade and ER and PR expression whereas no significant correlation was observed between tumor grade and HER2/neu expression. Our study corroborates with the study done by Saptarishi et al [28] where ER, PR status significantly correlated with the stage of the disease. Similar correlation was found in other studies [29].

Metastasis in axillary lymph nodes was seen in $37.5 \%$ of patients. About $54.55 \%$ ER $57.58 \%$ PR and \%HER2/neu positive cases had positive axillary lymph nodes positive for metastasis. In our study, we 
found that ER/PR expression had no significant correlation with lymph node metastasis. Also HER2/neu overexpression showed no significant association with lymph node metastasis and this result is in agreement with Almasri et al [30]. Unlike our study, Siadati et al 2015, showed significant association between HER2/neu overexpression and lymph node status [29].

\section{Conclusion}

Invasive ductal carcinoma of the breast cancer was seen in the age of 24 and $80 \mathrm{yrs}$, with a mean age of 56.6 years. The maximum number of cases were seen in the age above 50 years $(64.77 \%)$. Majority of the tumors that were ER and PR positive were of Grade II, whereas majority of HER2/neu positive tumors were of Grade III. This study showed that ER and PR are correlated with age, tumor size and tumor grade but not with lymph node status. HER2/neu expression are correlated with age only but not with tumor size, tumor grade and lymph node status. Therefore it is strongly recommended to assess the hormone receptors for clinical management of a breast cancer patient to provide prognostic information and therapeutic measurement.

\section{Declarations}

\section{Compliance with Ethical Standards:}

This work is approved by institutional ethical committee.

\section{Conflict of interest:}

The authors have no conflict of interest.

\section{Consent for publication:}

All the authors have given their consent to publish the article.

\section{Availibility of data and material:}

All the data generated and analysed during this study are included in this published article.

\section{Funding:}

This work is funded by DHR (Department of Health Research).

\section{Authors contribution:}

The authors $\mathrm{MN}, \mathrm{BC}, \mathrm{BB}, \mathrm{BD}$ contributed in analysing and interpreting the result. JS contributed in performing the experiment, ND contributed in performing the experiment, analysing the data, writing the manuscript.

\section{Acknowledgement:}


This work is funded by DHR (Department of Health Research).

\section{References}

1. Yadav R, Sen R, Preeti. Role of receptors in breast cancer. IJABR. 2012;2(4):561-571.

2. Jatoi I, Miller AB. Why is breast cancer mortality declining? Lancet Oncol. 2003;4(4):251-254.

3. Rastelli F, Crispino S. Factors predictive response to hormone therapy in breast cancer. Tumouri. 2008;94(3):370-383.

4. Dunnwald LK, Rossing MA, Li Cl. Hormone receptor status, tumor characteristics, and prognosis: a prospective cohort of breast cancer patients. Breast Cancer Res. 2007;9:R6.

5. Leake R. Comment. Breast. 2000; 9:270.

6. Immunohistochemistry Standard Operating Protocol. 2011.. Available from: http:/edrn.nci.gov/resources/standard-operating-procedures/assays/IHC/immunoperoxisdasestaining/sop-ihc.

7. Allred DC, Harvey JM, Berardo M, Clark GM. Prognostic and predictive factors in breast cancer by immunohistochemical analysis. Mod Pathol. 1998;11:155-68.

8. ASCO-CAP HER2/neu Test Guideline Recommendations. College of American Pathologists. 2013.

9. Musa AA, Aliyu UM. Application of Machine Learning Techniques in Predicting of Breast Cancer Metastases Using Decision Tree Algorithm, in Sokoto Northwestern Nigeria. J Data Mining Genomics Proteomics. 2020;11:220.

10. Malvia S, Bagadi SA, Dubey US, Saxena S. Epidemiology of breast cancer in Indian women. Asia Pac J Clin Oncol. 2017;13(4):289-95.

11. Hammond ME, Hayes DF, Dowsett M, Allred DC, Hagerty KL, Badve S, Fitzgibbons PL, et al. American Society of Clinical Oncology/College of American Pathologists guideline recommendations for immunohistochemical testing of estrogen and progesterone receptors in breast cancer. J Clin Oncol. 2010;28:2784-95.

12. Leong AS, Zhuang Z. The changing role of pathology in breast cancer diagnosis and treatment. Pathobiology. 2011;78:99-114.

13. Zaha DC. Significance of immunohistochemistry in breast cancer. World J Clin Oncol. 2014;5:382392.

14. Desai SB, Moonim MT, Gill AK, et al. Hormone receptor status of braest cancer in India: A study of 798 tumours. Breast. 2000;9(5):267-270.

15. Suvarchala SB, Nageswararao R. Carcinoma breast-histopathological and hormone receptors correlation. J Biosci Tech. 2011;2:340-348.

16. Mudduwa LK. Quick score of hormone receptor status of breast carcinoma:Correlation with the other clinicopathological prognostic parameters. Indian J Pathol Microbiol. 2009;52:159-63.

17. Singh R, Gupta S, Pawar SB, Pawar RS, Prabhudesai S. Evaluation of ER, PR and HER-2 receptor expression in breast cancer patients presenting to a semi urban cancer centre in Western India. 
Journal of Cancer Research and Therapeutics. 2014; volume 10-Issue 1.

18. AlZaman AS, Mughal SA, AlZaman YS, AlZaman ES. Correlation between hormone receptor status and age, and its prognostic implications in breast cancer patients in Bahrain. Saudi Med J. 2016;37:37-42.

19. Patnayak R, Jena A, Rukmangadha N, Chowhan A, Sambasivaiah K, 2015. Hormone receptor status (estrogen receptor, progesterone receptor), human epidermal growth factor-2 and p53 in South Indian breast cancer patients: A tertiary care centre experience. Indian J Med Paediatr Oncol. 2015;Apr-Jun; 36(2): 117-122.

20. Naghavi M. Breast and cervical cancer in 187 countries between 1980 and 2010: Asystematic analysis. Lancet. 2011;378:1461-84.

21. Raina V, Bhutani M, Bedi R, Sharma A, Deo SVS, Shukla NK. Clinical features and prognostic factors of early breast cancer at a major cancer centre in North India. Indian J Cancer. 2005; 42:40-45.

22. Elsayed M Ali, Ahmed R. H. Ahmed, Aymen M.A. Ali. Correlation of Breast Cancer Subtypes Based on ER, PR and HER2 Expression with Axillary Lymph Node Status. Cancer and Oncology Research. 2014; 2(4): 51-57.

23. Dodiya H, Patel A, Patel D, Kaushal A, Vijay DG. Study of hormone receptors and epidermal growth factor expression in invasive breast cancers in a cohort of Western India. Indian J Clin Biochem. 2013;28:403-9.

24. Ariga R, Zarif A, Korasick J, Reddy V, Siziopikou K, Gattuso P. Correlation of Her-2/neu gene amplification with other prognostic and predictive factors in female breast carcinoma. Breast J. 2005;11(4):278-80.

25. Bhatavdekar JM, Patel DD, Shah NG, Vora HH, Suthar TP, Ghikhlikar PR, et al. Prognostic significance of immunohistochemically localized biomarkers in stage II and stage III breast cancer: a multivariate analysis. Ann Surg Oncol. 2000;7(4):305-11.

26. Singh R, Gupta S, Pawar S B, Pawar R S, Gandham S V, Prabhudesai S. 2014. Evaluation of ER, PR and HER-2 receptor expression in breast cancer patients presenting to a semi urban cancer centre in Western India. Journal of cancer research and therapeutics. 2014; Volume 10: Issue 1.

27. Ghosh S, Sarkar S, Simhareddy S, Kotne S, Rao PBA, Turlapati SPV. Asian Pac J Cancer Prev. 2014; 15(18), 7839- 7842.

28. Zhou XL, Fan W, Yang G, Yu MX (2014). The clin ical significance of PR, ER, NF-kB and TNF-a in Breast cancer. Dis Markers, 494581.

29. Almasri N M, Al HamadM.Immunohistochemical evaluation of human epidermal growth factor receptor 2 and estrogen and progesterone receptors in breast carcinoma in Jordan. Breast Cancer Res, 7: 598- 604, 2005.

30. Siadati S, Sharbatdaran M, Nikbakhsh N, Ghaemian N. (2015). Correlation of ER, PR, HER2/Neu with other Prognostic Factor in Infiltrating Ductal Carcinoma of Breast. Iran J Pathol, 10(3): 221- 226.

\section{Figures}




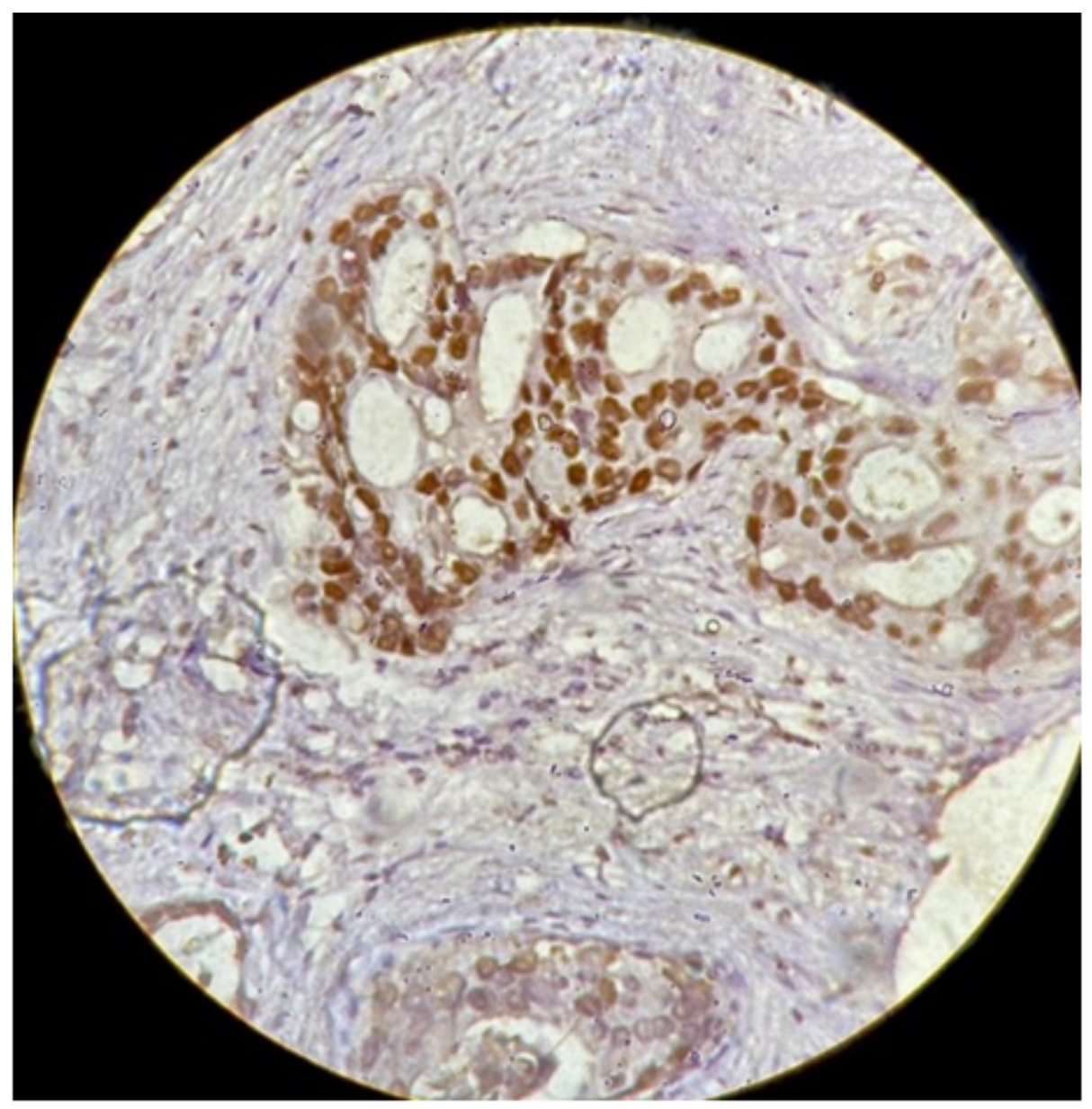

Figure 1

Immunohistochemical staining showing positive for ER 


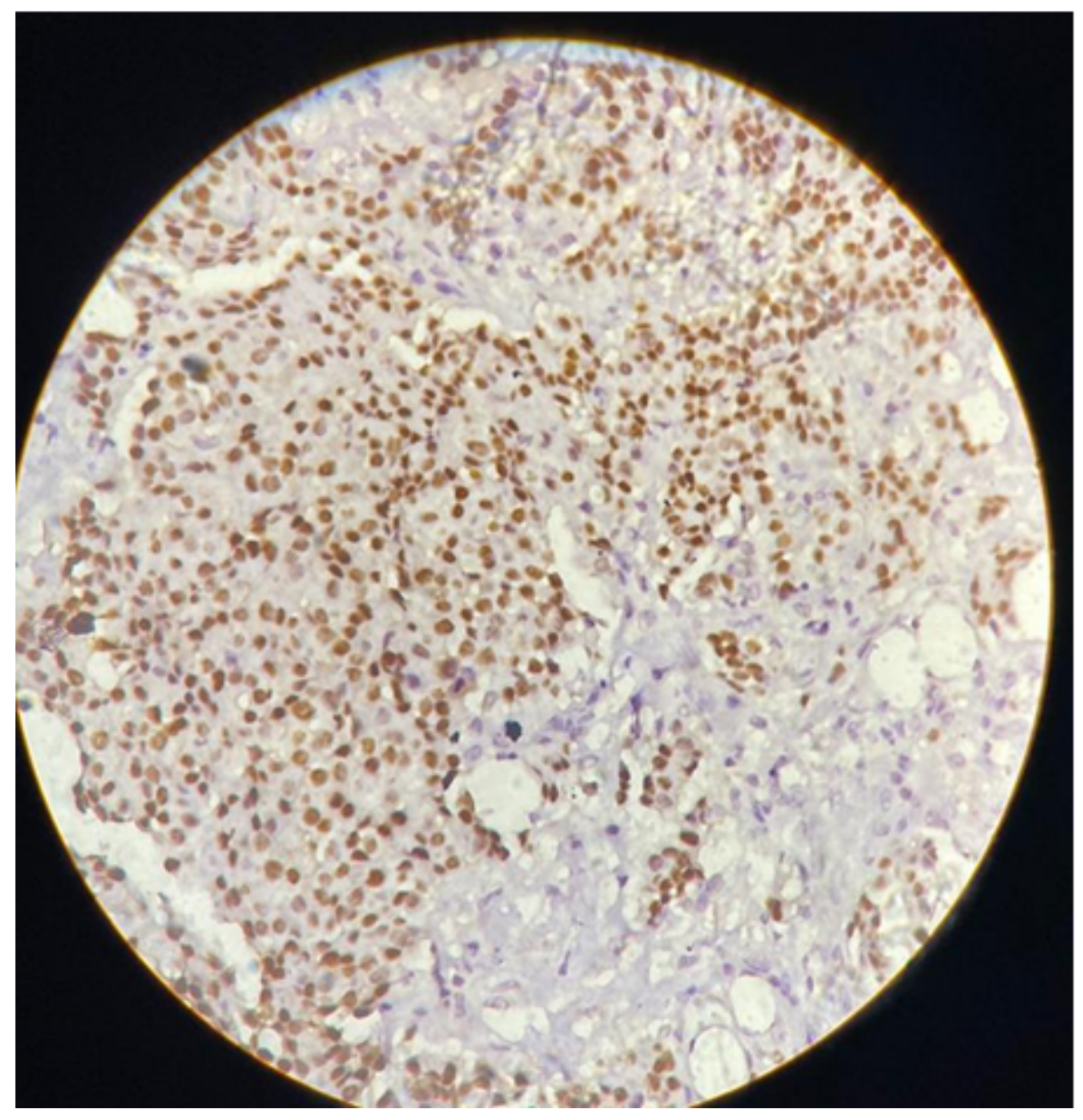

Figure 2

Immunohistochemical staining showing positive for PR 


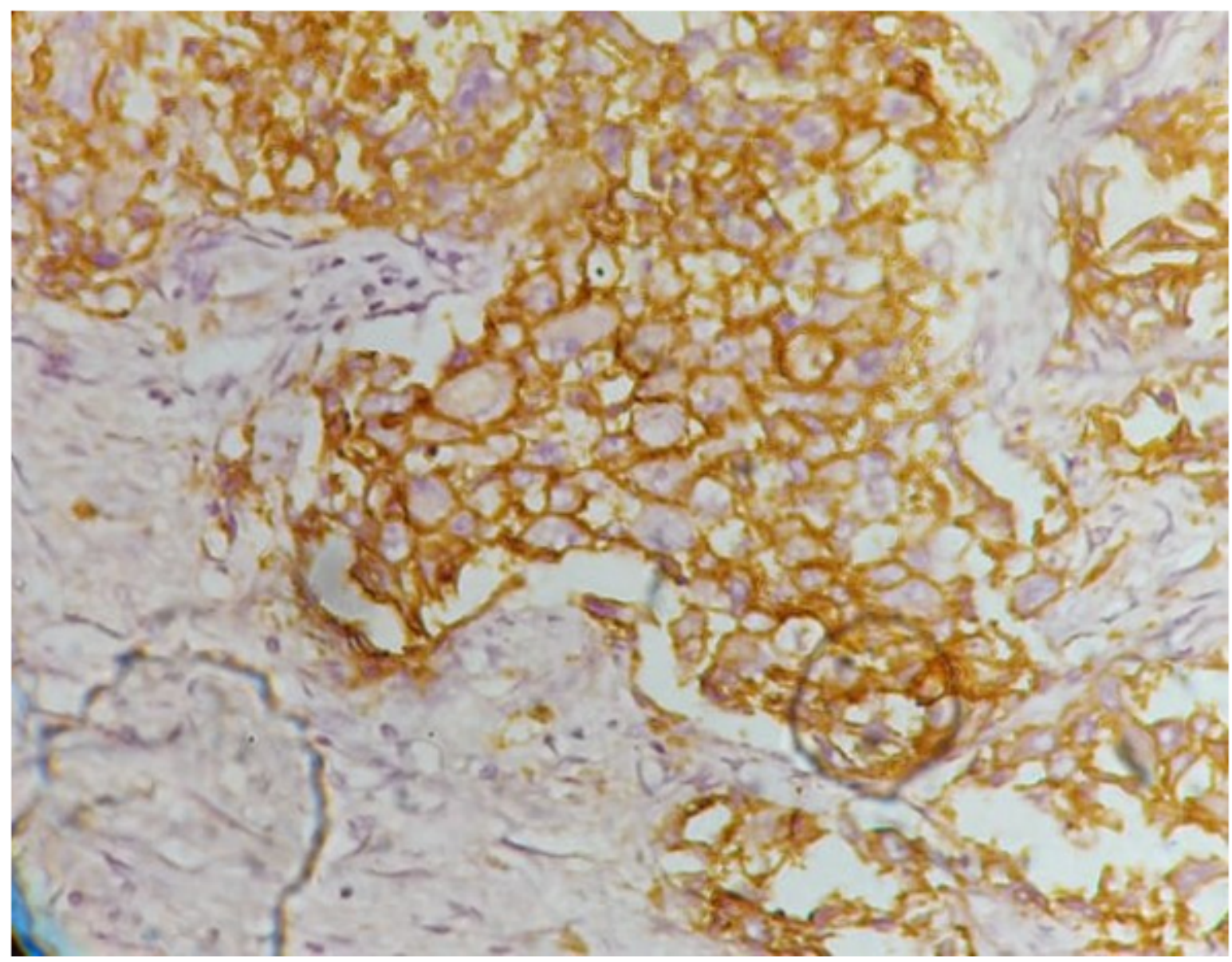

\section{Figure 3}

Immunohistochemical staining showing positive for HER2/neu 